\title{
The Effects of Review Presentation Formats on Consumers' Purchase Intention
}

\author{
Cong Li, Xidian University, China \\ Yuming Liu, Xidian University, China \\ Rong Du, Xidian University, China
}

\begin{abstract}
Perception of products has become one of the most important factors influencing consumers' purchase intention in the context of online shopping. Thus, enriching and studying review presentation formats have been significant things for practitioners and researchers. This study employed dual coding theory and telepresence theory to investigate the effects of review presentation formats (text-based reviews, image-based reviews, and video-based reviews) on consumers' purchase intention and then analysed the moderation effect of product type. The $3 \times 2$ between-subject situational experiment and $3 \times 2$ within-subject eye-tracking experiment design were separately applied to test the hypotheses. The results manifested that review presentation formats exactly could generate different impacts on consumers' purchase intentions. And product type moderated the impact of presentation formats on purchase intentions. Hence, this research considered that online vendors should pay more attention to image-based and video-based reviews and, moreover, take the product type into account.
\end{abstract}

\section{KEYWORDS}

Product Type, Purchase Intentions, Review Presentation Formats

\section{INTRODUCTION}

As a major way for consumers to obtain product information when they are shopping online, online reviews significantly influence purchase decisions of consumers (Ahmad \& Laroche, 2016; Zhu \& Zhang 2010), and also provide a large amount of product and market information for vendors (Cui et al., 2012; Duan et al., 2008). Benefiting from the popularity of smart phones, tablets and other smart devices possessing high-quality photos taking and videos recording, image-based reviews and videobased reviews gradually emerge on some leading vendors websites. In the study, text-based reviews refer to reviews, uploaded by consumers, barely contain text information. However, image-based reviews include text and image information, and texts combined with videos are shown in videobased reviews. In practice, the images and videos compared with texts can offer more multisensory cues and dynamic information to display product (Xu et al., 2015). Head of JD, e-commerce giant in China, once indicated that the short video would become the standard configuration information of the product digitization. Besides, some shopping websites have been stimulating consumers to post pictures or videos by cash rewards in order to attract more buyers and add more sales, and labeling "images or videos" to facilitate consumers to search all images and videos more speedily in 
China. Alike practitioners, scholars are also concentrated on how review presentation formats affect consumers' decisions.

Purchase intentions can be considered as the degree of consumers intend to buy the products (Botha \& Reyneke, 2015). Scholars have widely examined the factors that promoted purchase intentions to consumers. Previous researchers have shown the impact of review characteristics on purchase intentions, such as review quantity (Park et al., 2007), and perceived trust (Awad \& Ragowsky, 2008), perceived risk (Chiu et al., 2013; Dai et al., 2014) had an influence on purchase intentions. However, vast of the researches have concerned on text-based reviews, which was the main presentation formats over the past years. With the popularity of smart devices and demand of consumers, scholars gradually turned to study other presentation formats, such as image-based reviews or video-based reviews (Liu \& Du, 2019; Xu et al., 2015; Yoo \& Kim, 2014). But their conclusions were inconsistent. Compared with image information, video-based reviews could provide more detailed product information, thus increasing consumers' perceived value (Yin et al., 2021). Compared with text-based reviews, imagebased reviews provided higher perceived product understanding ((Liu \& Du, 2019). Some scholars had different opinions, which found that consumers were more dependent on text information, image information was just a verification of the text expression (Hughes et al., 2003). Thus, to clarify this relationship, the study prepares to further examine the influence of review presentation formats of text-based reviews, image-based reviews and video-based reviews on purchase intentions.

A key of impediment of online shopping is the lack of sensory experience on the computer screen. Researchers have demonstrated that perception of products have become one of the most remarkable factors influencing consumers' intentions regarding shopping online (Jiang \& Benbasat, 2007). Consequently, the first question the research focuses on becomes particularly important: (1) Which review presentation formats have higher impact on purchase intentions for consumers. In addition, the behaviors of consumers' seeking and learning depend on product type, that is to say different kinds of information adapt to different product type (Xu et al., 2015; Mudambi \& Schuff, 2010). So, the second question to discuss: (2) Under the comparison of different product types, each review presentation formats can provide higher impact on purchase intention for different product type.

The study organizes the paper as follows. First, the study uses the dual code theory and telepresence theory as theoretical background to develop the research model. Then the study confirms the model employing two experiments. After, the study discusses the results. Finally, this study indicates management contributions and limitations.

\section{THEORETICAL BACKGROUND AND HYPOTHESES}

\section{Dual Coding Theory}

Based on dual coding theory (DCT), the human cognitive system includes two both separate and interrelated code systems, verbal code system and nonverbal code system, which play an important role in the process of learning and memory (Bywaters et al., 2004). One of them directly deals with verbal information, such as text information, and the other conforms to handle nonverbal information, such as image information or video information (Paivio, 1991). When the consumers apply two code systems in information processing simultaneously, the verbal representation and nonverbal representation could form connections, enriching the paths of information acquisition and improving the learning and memory effects of consumers (Paivio \& Ernest, 1971). Therefore, compared with only text information, the combination of text sand images or texts and videos is more successful to acquire information for consumers. Additionally, it is believed the verbal information active in left hemisphere of brain, whereas non-verbal generate more activation in the right (Geschwind, 1979; Childers \& Jiang, 2008). The information including texts and images or videos will active in left and right hemisphere of brain (Buckner et al., 1999). 
In this study, image-based reviews, uploaded by consumers, are made up of texts and images, in the meanwhile, there exist not only texts, but videos in the video-based reviews. Consistent with dual coding theory, when consumers browse image-based reviews or video-based reviews, verbal code system and nonverbal code system deal with information altogether to strengthen consumers' memory, which makes the performance effects of both online reviews more dynamic and specific. Furthermore, consumers are required to take pictures or videos and edit texts, such cumbersome steps will cost more time and execution cost that the image-based reviews or video-based reviews are more valuable, greatly improving the trusts of consumers. American scholars once made a comparative study about the reading effects of the illustrated and no illustrated textbook, which showed that the reading effects of the illustrated textbook were more prominent and the subjects obtained $25 \%$ more information from illustrated textbook than no illustrated (Levie \& Lentz, 1982). The images or videos in image-based online reviews or video-based online reviews reinforce text content in the reviews, and present products to consumers in multisensory respects. Hence, this study hypothesizes:

H1a: Image-based reviews provide higher impact on purchase intention for consumers than textbased reviews.

H1b: Video-based reviews provide higher impact on purchase intention for consumers than textbased reviews.

\section{Telepresence Theory}

The lack of physical contact has become one key deterrent of online shopping between products and consumers for a long time (Lee \& Park, 2014; Overmars \& Poels, 2015), so e-retailers have already committed to rich multisensory experiences to mimic reality. Telepresence is a psychological state of "being immersed" or of "being there" within the virtual world (Mollen \& Wilson, 2010), which is affected by how closed quality and quantity of simulated sensory information about the product (Fiore, 2005), respectively labels as "vividness" and "interactivity" (Steuer, 1992). Vivid and interactive information has been acknowledged as pivotal of online product presentation (Coyle \& Thorson, 2001), and has the possibility to give the consumer more intuitive product experience (Nowlis et al., 2004), thus reducing the uncertainty to the products and influencing their attitudes (Li et al., 2003).

Text-based reviews could only express the experience and feelings of consumers who have purchased through text, whereas image-based reviews supply consumers with visual and static contents (Jiang \& Benbasat, 2007). Video-based reviews provide more realistic audiovisual perception and dynamic information (Xu et al., 2015; Jiang \& Benbasat, 2007). The temporal visual pictures and relational sound of video-based reviews can cooperate with each other, thus generate more thorough representation of vivid and interactive information than image-based online reviews which only supply static pictures (Orús et al., 2016). The sensory information provided by texts, images and videos is increasing in turn, and the vividness and interaction of the three are improved in turn. H1a and $\mathrm{H} 1 \mathrm{~b}$ could be depicted again. In addition, video-based reviews are able to bring consumers more sensory information and deeper understanding than image-based reviews (Park \& Hopkinss, 1992), and then video-based reviews afford a higher sense of telepresence than image-based reviews (Nah, 2011). Thus, video-based reviews provide higher impact on purchase intention for consumers than image-based reviews.

Telepresence has been identified as a crucial factor to influence consumer behavior such as perceived trust (Lee \& Shin, 2014; Lu et al., 2016), perceived safe (Shin \& Shin, 2011) and purchase intention (Keng et al., 2016). Previous researches have shown that telepresence has a positive effect on purchase intention (Wang et al., 2019; Elsamari \& Mignon, 2016). Furthermore, researchers have shown that video-based online reviews are relatively effective in promoting purchase intention $\mathrm{Xu}$ et al., 2015). Hence, this study hypothesizes: 
H2: Video-based reviews provide higher impact on purchase intention for consumers than imagebased reviews.

\section{Product Type}

The nature of online shopping determines consumers have to apply incomplete information to make purchase decisions as they may be shortage of product quality, using experience and other information (Mudambi \& Schuff, 2010). Looking for useful information has been acknowledged so costly and time consuming that consumers must make trade-offs between the cost and benefits from search (Stigler, 1961). Additionally, the studies have shown that the total cost of product contains not only the mere value of product but the cost of search that is considered made up of physical search and cognitive processing efforts (Nelson \& Phillip, 1970). The development of the internet has forced consumers to face the situation of information explosion, and simultaneously the search cost is becoming higher. Features of the product are widely noted as the key factor that influences the search cost (Mudambi $\&$ Schuff, 2010). The most common classification is to divide the products into search goods and experience goods based on whether consumers could judge the value of the products before purchase (Luan et al., 2016; Xu et al., 2015; Huang et al., 2009), but the classification was more applied in the context of text-based reviews and did not take multisensory information into account. Besides, the purpose of this research is to study different review presentation formats, whose main discrimination is that different review presentation formats can provide consumers different sensory information, have an impact on consumers' purchasing decisions. Therefore, this research distinguishes products into sensory goods and nonsensory goods according to whether product attributes can be perceived by consumers (Pauwels et al., 2011; Degeratu et al., 2000), which classification is more consistent with the goal of the research. Consumers make purchase decision based on sensitive cognition or rational analysis to evaluate product attributes (Citrin et al. 2003; Joann \& Childers, 2003). For some product attributes, such as inferring the taste of food with visual stimuli or evaluating the material of clothing with touch, consumers make an intuitive evaluation through sensory perception, so called sensory attributes (Pauwels et al., 2011). But for those attributes that cannot be sensed, such as product ingredients, consumers need to be objectively judged by rational analysis, so called nonsensory attributes (Pauwels et al 2011). Sensory goods have a greater weight of sensory attributes, which require the intuitive and subjective feelings of the consumers to evaluate the product, and the results of the evaluation vary from person to person. Nonsensory goods with a larger proportion of nonsensory attributes, must be logically analyzed and processed by consumers, and the approximately the same evaluation level could get from different consumers.

Consumers require diagnostic information consistent with different product type (Liu \& Du, 2019; Hassanein \& Head, 2005). Text information is precisely applied to depict the nonsensory attributes (Nelson, 1974), which is characterized by abstraction, coreness, and de-backgroundization, and is more helpful for receivers to accurately understand the core ideas (Bar, 2004); while image information or video information is normally used to describe sensory attributes, which exists features of concreteness, intuitiveness and backgroundization, and images and videos can present specific products to the recipient (Stenberg \& Georg, 2006; Glaser, 1992), and visual or auditory sense of goods usually are more difficult to describe by text information alone (Jiang \& Benbasat, 2007). Therefore, diagnostic information that consumers need are significantly distinct for different product type (Mudambi \& Schuff, 2010). Appropriate information is beneficial to reduce uncertainty and time consuming before making purchasing decision. The evaluation of nonsensory goods is manifested as objective and logical, and consumers' utility level does not change due to consumers' subjective feelings. Thus, text-based reviews help to accurately explain the non-sensory attributes, and influence purchase decision of nonsensory products. On the other hand, the evaluation level of sensory products depends largely on the consumers' sensory pleasure and emotional experience, and images and videos can make up for sensory experience that consumers lack online shopping. Thence, 
image-based reviews or video-based reviews have a greater impact on improving consumers' purchase intention of sensory products. Hence, this study hypothesizes:

H3a: Text-based reviews provide higher impact on purchase intention to consumers for nonsensory goods compared to sensory goods.

H3b: Image-based reviews provide higher impact on purchase intention to consumers for sensory goods compared to nonsensory goods.

H3c: Video-based reviews provide higher impact on purchase intention to consumers for sensory goods compared to nonsensory goods.

\section{Eye Tracking and Fixation Duration}

With the advancement of information technology and neuroscience, neurocognitive and neuropsychological methodologies have been widely used in consumer behavior (Russo, 1978). Eye tracking, applied in consumer behavior since 1900 (Wang \& Minor, 2008), is a method to identify specific eye tracking and even observe the cognitive process of consumers, which can be applied to find out how visual stimuli affect consumer strategies. Chae et al., once demonstrated consumers' fixation process is the most effective way to obtain information from the outside. Previous researches suggested that the process of gazing at visual stimuli represents subjects are paying attention to the stimuli, so the eye tracking could reflect perceptual and cognitive process (Just \& Carpenter, 1976), and further can predict consumer behavior.

Fixation duration and fixation count are the main parameters of eye tracking device. Fixation duration is a period of time spend on gazing at visual stimuli, and the longer fixation duration means the more the brain interprets the region and consumers are more interested in the area (Luan et al.,2016), Area of interest (AOI) is a term in the field of eye tracking, which can be explained the region the consumers might be interested. Longer fixation duration on area of interest (AOI) indicates that the area is more attractive or it is difficult to extract information (Ehmke \& Wilson, 2007). Fixation count is the number of fixation points, also a parameter reflecting the importance of the area of interest (AOI) (Duque \& Vázquez, 2015). Since the fixation duration and fixation count have a similar explaining function to area of interest, and some scholars believe that fixation duration in the region is the best index to compare the distribution of attention on different targets (Pieters, 2000). Hence, this research chose fixation duration as the parameter to explain degree of concern of area of interest. Normally, consumers attach importance to the contents that they are interested for a longer time, and pay attention to the contents they are not interested for a shorter time. When it comes to the context of online reviews, if the product type matches the review presentation formats, the fixation duration of the area of interest is longer. Combined with the above mentioned, hence, this study hypothesizes:

H4a: The fixation duration of consumers on text-based reviews will be longer for nonsensory goods compared to sensory goods.

H4b: The fixation duration of consumers on image-based reviews will be longer for sensory goods compared to nonsensory goods.

H4c: The fixation duration of consumers on video-based reviews will be longer for sensory goods compared to nonsensory goods.

The Figure 1 has shown the theoretical model of this research. 

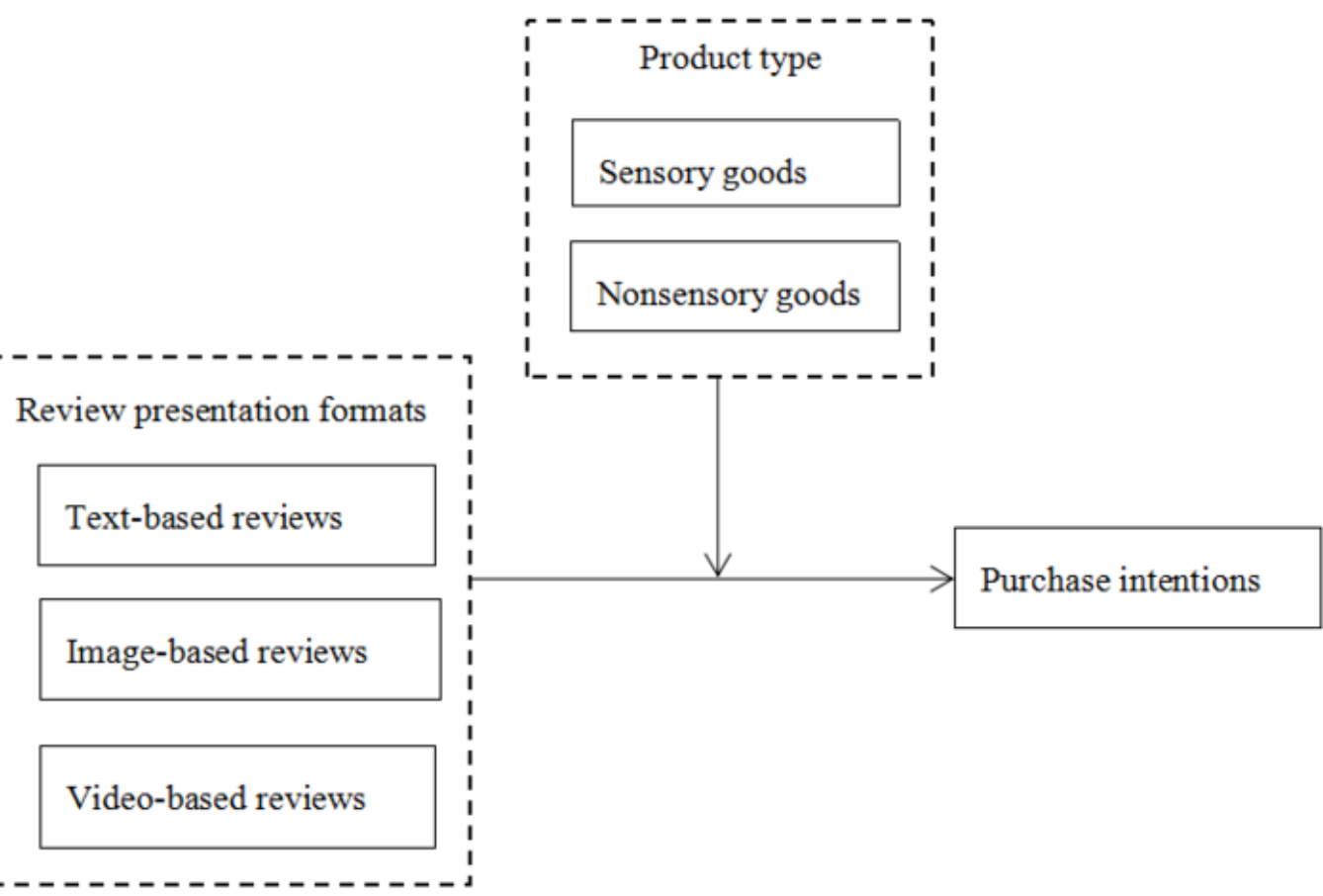

\section{RESEARCH METHOD 1}

The purpose of the research method 1 conducted an experiment is to study the effects of three kinds of review presentation formats on purchase intention and investigate the moderate factor of product type. Clearly, the section is to test $\mathrm{H} 1$ (H1a, H1b), H2 and H3 (H3a, H3b, H3c). The study adopted a between-subject design that is 3 (text-based vs. image-based vs. video-based online reviews) $\times 2$ (sensory vs. nonsensory product).

\section{Selection of Products}

Based on previous research, this study chose two kind of products marketed on Taobao.com as shown in Table 1. Corresponding to classification standard of product type, the authors chose clothing as sensory goods. Evaluating the clothing demand to use some senses and need the subjective evaluation of the consumers, and the results vary from person to person (Pauwels et al., 2011; Mudambi \& Schuff, 2010). Before purchasing in the online shopping context, the consumers can not acquire full information about the clothing (Song et al., 2007). For example, the colour and thickness of the clothing require the visual sensation and the softness and warmth demand the tactile sensation, which are the two major sensory perceptions to assess the clothing. Moreover, considering the impact of the gender on consumers' habit, this study simultaneously chose women's denim jacket and men's casual jacket as the sensory products. As for the nonsensory goods, the book was selected for the following reason. The main attributes of the novel, such as the quality of the paper and clarity of contents, were objective and the full information was obtained before reaching consumers.

\section{Stimulus Materials}

In order to make consumers perceive more authentic shopping experience, the online reviews of the study were chosen from the Taobao.com, which were uploaded thousands of images and videos by 


\begin{tabular}{|c|c|c|l|}
\hline Product & Description & \multicolumn{1}{c|}{ Type } & \multicolumn{1}{c|}{ Sources } \\
\hline \multirow{3}{*}{ Clothing } & $\begin{array}{c}\text { Women's denim jacket } \\
\text { Men's casual jacket }\end{array}$ & Sensory & $\begin{array}{l}\text { Citrin et al., (2003), } \\
\text { Baal \& Dach (2005), } \\
\text { Pauwels et al.,(2011). }\end{array}$ \\
\hline \multirow{2}{*}{ Book } & A novel & Nonsensory & $\begin{array}{l}\text { Burke (2002), } \\
\text { Citrin et al.(2003), } \\
\end{array}$ \\
& & & Pauwels et al.,(2011). \\
\hline
\end{tabular}

the consumers who have already bought the products. This study only considered the positive reviews, which means good texts for text-based reviews, neat and clear images for image-based reviews, fluent and bright videos for video-based reviews. The text-based reviews selected have been properly modified to guarantee contents clear and easy to understand. The text-based reviews had three texts. The image-based reviews contained the same texts with the text-based online reviews, and followed three images under each text-based reviews. The video-based reviews also included the same text contents, and accompanied a video below each text-based reviews.

In addition, the study had applied some ways to avoid the effects of different quality of review presentation formats between different products on consumers' purchase intention. For text-based reviews, the research kept the length within 50 words to make the positive reviews easier to understand. For image-based reviews, the study controlled the images emotions as positive, the pertinence and Integrity as the products could be fully presented, clarity of images, almost solid background. For video-based reviews, the research held the length within about 10 seconds, the pertinence and integrity, clarity, fluency, almost solid background.

\section{Experimental Procedures}

The participants of this study were undergraduate students from Xidian University. This study adopted a between-subject design to avoid learning effects of the participants (Xu et al., 2015). That is to say, if a participant firstly read the image-based reviews or video-based reviews, after view the text-based reviews about the same product, images or videos would have an impact on purchase decision when reading the text-based reviews. Moreover, in order to preclude the effect of gender on the experiment, the participants were randomly divided into six groups. Every group had sixty participants, including 30 women and 30 men. Participants had online shopping experience, and tended to read online reviews before they bought the products. Finally, the results contained invalid results 6 , valid results 354 referring to 179 men and 175 women.

This study was divided into three stages to enhance the reliability of experimental procedures. First, participants were claimed to sit randomly and separately to guarantee that they could not glance others' screen and discuss with each other. Second, the authors instructed participants a mobile application, called WeChat, via which the participants used a specific function, named "Scan QR Code" to receive the questionnaires that the authors had done. The product descriptions were provided so that consumers could understand the product more clearly, then followed the online reviews mentioned above. Finally, after reading the online reviews, the participants were required to answer the questions of their perceptions on purchase intention. After submission, the participants would gain a chance to conduct lucky draw, via which they could acquire different rewards. Purchase intention was measured by four items from Lin \& Chen (2005). All responses were measured on a 


\begin{tabular}{|c|c|c|}
\hline \multirow{4}{*}{$\begin{array}{l}\text { Purchase } \\
\text { intenton }\end{array}$} & I have a great opportunity to buy the product. & \multirow{4}{*}{$\begin{array}{c}\text { Gefen \& Straub (2004), } \\
\text { Lin\&Chen (2005). }\end{array}$} \\
\hline & I wish to buy the product. & \\
\hline & I will make the product as my first choice. & \\
\hline & $\begin{array}{l}\text { I'm likely to recommend the product to someone } \\
\text { else. }\end{array}$ & \\
\hline
\end{tabular}

seven-point Likert scale ranging from 1 (extremely disagree) to 7 (extremely agree). Measurement used in this study was shown in Table 2.

\section{RESULTS}

\section{The Constructs Reliability and Validity}

Purchase intention is the indicator to measure the likelihood that consumers would purchase the products. The stronger the willingness of consumers to buy, the greater the likelihood that consumers will purchase (Schiffman \& Kanuk, 2000). The study applied Cronbach's alphas and factor loading, respectively, to test the scale of the purchase intention's reliability and validity, as shown in Table 3. The Cronbach's alphas for the purchase intention was 0.823 , demonstrating the scale had good internal-consistency. Next, all the factor loadings were higher than 0.7 , testifying that the scale have better reflected the purchase intention.

\section{Test of Hypotheses}

The research used the ANOVA (Analysis of Variance) to test the hypotheses. The results of fixed effect were shown in Table 4. Then the research applied simple effect test to identify an interaction effect between product presentation format and product type.

\section{Table 3. Constructs of reliability and validity}

\begin{tabular}{|l|c|c|}
\hline & $\begin{array}{c}\text { Cronbach's } \\
\text { alphas }\end{array}$ & \multicolumn{1}{|c|}{$\begin{array}{c}\text { Factor } \\
\text { loading }\end{array}$} \\
\hline I have a great opportunity to buy the product. & & 0.816 \\
\hline I wish to buy the product. & & 0.839 \\
\hline I will make the product as my first choice. & & 0.823 \\
\hline $\begin{array}{l}\text { I'm likely to recommend the product to } \\
\text { someone else. }\end{array}$ & & 0.73 \\
\hline
\end{tabular}




\begin{tabular}{|l|c|c|c|}
\hline & Variable & F & Sig \\
\hline Review presentation formats & PI & 25.792 & 0.000 \\
\hline Product type & PI & 4.517 & 0.034 \\
\hline Review presentation formats x Product type & PI & 6.899 & 0.001 \\
\hline
\end{tabular}

PI: purchase intention

The first concern concentrated on the difference in purchase intention across different review presentation formats. As shown in Table 4, the results of analysis indicated that the main effect of product presentation format was significant on purchase intention $(F=25.792, p<0.001)$. Furthermore, perceived influence of review presentation formats as illustrated in Figure 2, the study can get that viewing image-based review had a higher purchase intention $\left(\mathrm{M}_{\text {image }}=4.3181\right.$ versus $\mathrm{M}_{\text {text }}=3.6902$, $\mathrm{t}=-4.535, \mathrm{p}<0.001)$ than did those text-based review. In the same way, participants viewing videobased review had a higher purchase intention $\left(\mathrm{M}_{\text {video }}=4.6907\right.$ versus $\left.\mathrm{M}_{\text {text }}=3.6902, \mathrm{t}=-7.194, \mathrm{p}<0.001\right)$ than did those text-based reviews. Finally, viewing video-based had a higher purchase intention $\left(\mathrm{M}_{\text {video }}=4.6907\right.$ versus $\left.\mathrm{M}_{\text {image }}=4.3181, \mathrm{t}=-2.480, \mathrm{p}<0.05\right)$. In summary, the results supported $\mathrm{H} 1(\mathrm{H} 1 \mathrm{a}$, $\mathrm{H} 1 \mathrm{~b})$ and $\mathrm{H} 2$.

Following, the study focused on the moderation effect of product type. As shown in table 4, not only the main effects of product presentation formats $(\mathrm{F}=25.792, \mathrm{p}<0.001)$ and product type $(\mathrm{F}=4.517$, $\mathrm{p}<0.05)$ were significant, but the interaction effect between review presentation formats and product type was significant $(\mathrm{F}=6.899, \mathrm{p}<0.05)$. In addition, as shown in Figure 3, the research found that text-based reviews generate greater positive influence on purchase intention, for nonsensory goods to search goods $\left(\mathrm{M}_{\text {nonsensory }}=3.8707\right.$ versus $\left.\mathrm{M}_{\text {sensory }}=3.5127, \mathrm{t}=-2.037, \mathrm{p}<0.05\right)$. When product type is sensory goods, image-based reviews have larger positive impact on purchase intention, compared to nonsensory goods $\left(\mathrm{M}_{\text {sensory }}=4.5864\right.$ versus $\left.\mathrm{M}_{\text {nonsensory }}=4.0542, \mathrm{t}=2.576, \mathrm{p}<0.05\right)$. Simultaneously, video-based reviews have greater positive effect on purchase intention, for sensory goods to nonsensory goods $\left(\mathrm{M}_{\text {sensory }}=4.9625\right.$ versus $\left.\mathrm{M}_{\text {nonsensory }}=4.4095, \mathrm{t}=2.657, \mathrm{p}<0.05\right)$. All in all, the results above mentioned supported H3 (H3a, H3b, H3c).

\section{RESEARCH METHOD 2}

The part of the research method 2 implemented an eye-tracking experiment was to test the impacts of three kinds of review presentation formats on fixation duration and explore the moderation effect of product type. Specifically, the eye-tracking was to verified H4 (H4a, H4b, H4c). 40 undergraduate students from Xidian University were recruited to participate in eye-tracking experiment, and every of them could receive a notebook as a reward. Participants were divided into two group, one for sensory goods and another for nonsensory goods. Finally, among 39 participants were validated, and one for sensory goods performed invalidation as eye movements appeared free state.

\section{Experimental Design}

The consumers could browse the different review presentation formats based on their own consideration in real life, so the eye-tracking method applied a $3 \times 2$ within-subject design to imitate real shopping 
Figure 2. Perceived influence of review presentation formats

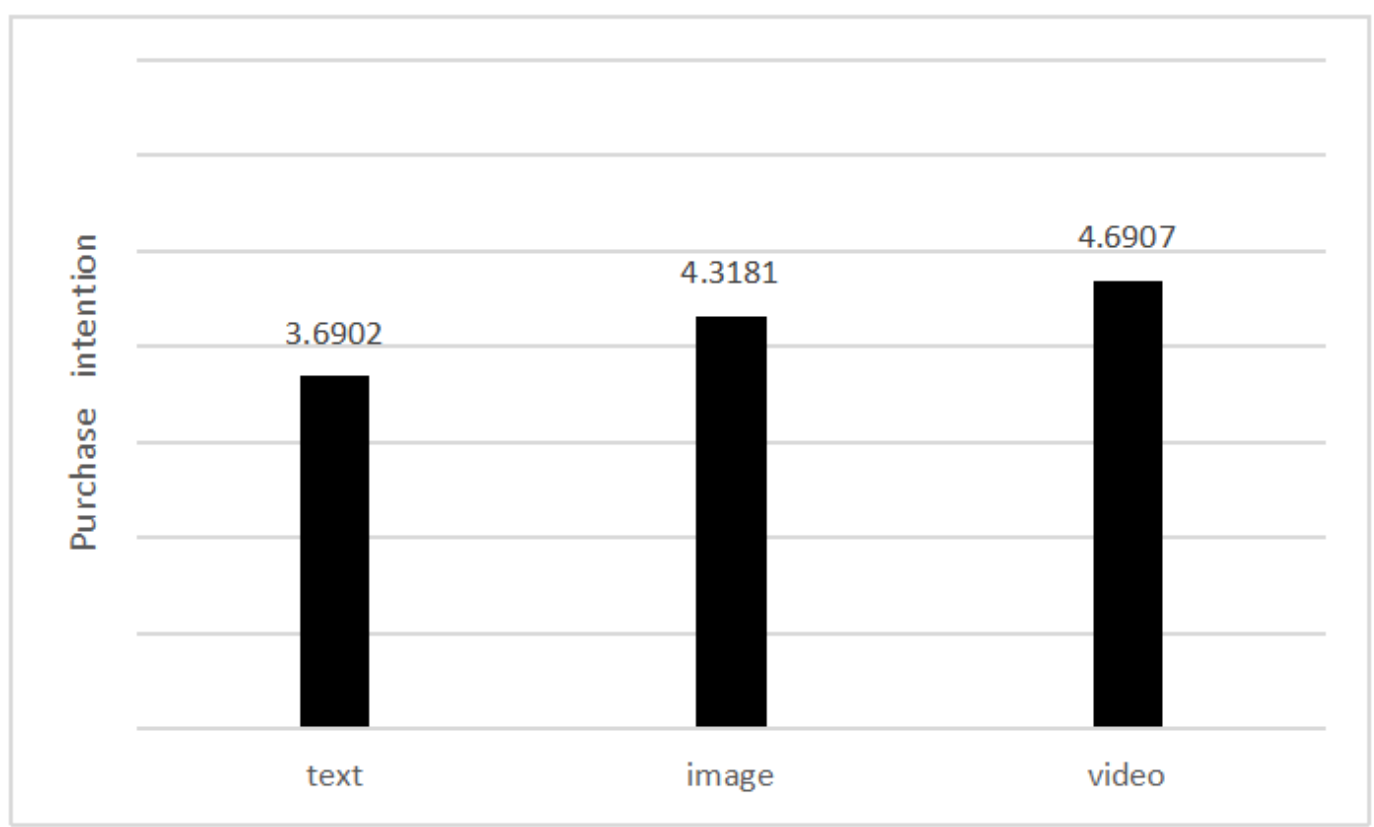

Figure 3. Interaction effect between presentation formats and product type

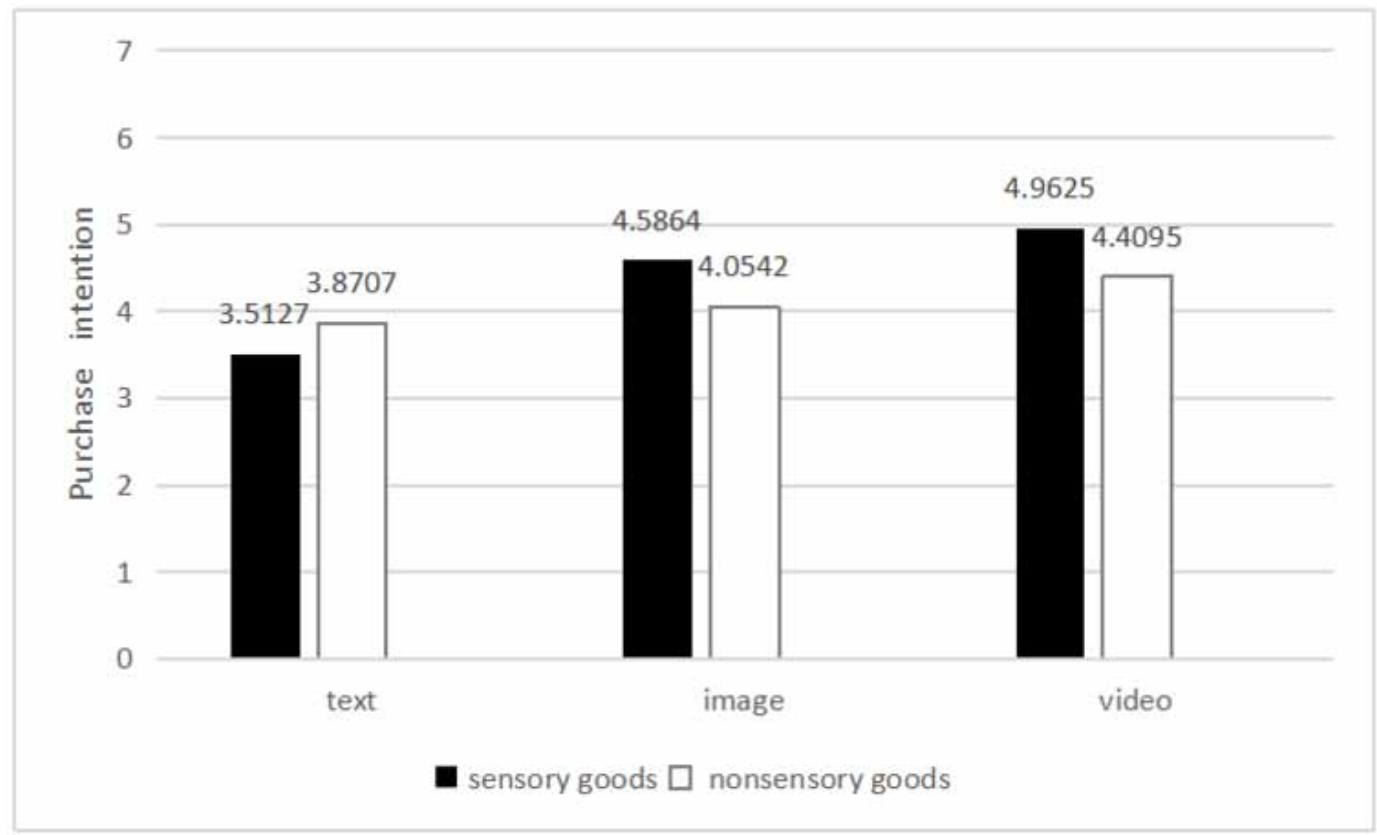


experience. In detail, the study divided the area of reviews into three parts, clearly, the left containing text-based reviews, the middle including image-based reviews, and the right was video-reviews. The selection criteria of stimulus materials of reviews were the same as the research method 1 , and the product type were also selected the clothing and the book.

\section{Experimental Procedures}

In the experiment, materials were displayed on a monitor and the subjects' eye movements were tracked and recorded by SMI Iview X RED eye-tracker. The eye-tracking experiment was divided into three parts to ensure validity of results. First, the subjects were told that they hoped to buy the product presented, and had the enough time to look the reviews to know more about the product. Second, the authors reminded participants to read the reviews that they want to watch, in order to avoid the subjects to browse all of the reviews. Finally, the authors needed to calibrate and validate sight of the subjects to guarantee eye movements tracked correctly. After, the experiment began, and eye movements of subjects were recorded by eye-tracker.

\section{RESULTS}

\section{Heat Map Analysis and Results}

Heat map could reflect the degree of the subjects' attention to the materials, and then in the study indicate the difference of fixation to three kinds of presentation formats for different product type. In a heat map, the degree of attention was shown in different colors. Red represented the highest level of fixation, followed by yellow, green and blue in turn, and no color means without fixation. The authors divided the stimulus materials into three area of interest (AOI), AOI 001 with text-based reviews, AOI 002 with image-based reviews, and AOI 003with video-based reviews, as shown in Figure 4 taking nonsensory goods as an example.

Consumers' fixation degree of three kinds of presentation formats for different product type were shown in Figure 5 and Figure 6. Comparing colors of Figure 5 and Figure 6, the fixation degree of the clothing and the book existed obvious differences. Specifically, the more yellow and blue in the text-reviews of the book were presented, which manifested the text-based reviews attracted more interest for nonsensory goods to sensory goods. The more red and yellow in image-based reviews of the book were displayed, which indicated fixation duration of consumers on image-based reviews would be longer for nonsensory goods compared with sensory goods. And the more red and yellow were shown in video-based reviews of the clothing, which implied the fixation degree of video-based reviews would be higher for sensory goods compared to nonsensory goods.

\section{Data Analysis and Results}

The study used the t-test and ANOVA (Analysis of Variance) to test the influence of three kinds of presentation formats on fixation duration. The results revealed the effect of presentation formats was significant on average fixation duration $(\mathrm{F}=5.076, \mathrm{p}<0.01)$, but the impact of product type was not significant on average fixation duration $(\mathrm{F}=0.484, \mathrm{p}=0.488>0.5)$, which reason were considered as the counteracting effect of different presentation formats on fixation duration in the different product type situation. That is to say, the average fixation duration of text-based and image-based reviews would be longer for nonsensory goods compared with sensory goods, but the average fixation duration of video-based reviews would be longer for sensory goods compared to nonsensory goods. The data were displayed in Table 5.

The interaction effect between presentation formats and product type was significant $(\mathrm{F}=4.441$, $\mathrm{p}=0.014<0.05$ ). Interaction effect between presentation format and product type as shown in Figure 7 , the research indicated that the fixation duration of text-based reviews would be longer for sensory goods to nonsensory goods $\left(\mathrm{M}_{\text {sensory }}=161.91\right.$ versus $\left.\mathrm{M}_{\text {nonsensory }}=218.44, \mathrm{t}=-2.305, \mathrm{p}<0.05\right)$. However, 


\section{Figure 4. Display of AOI for nonsensory goods}

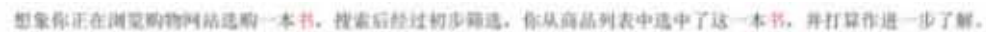

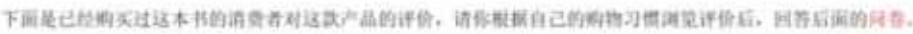
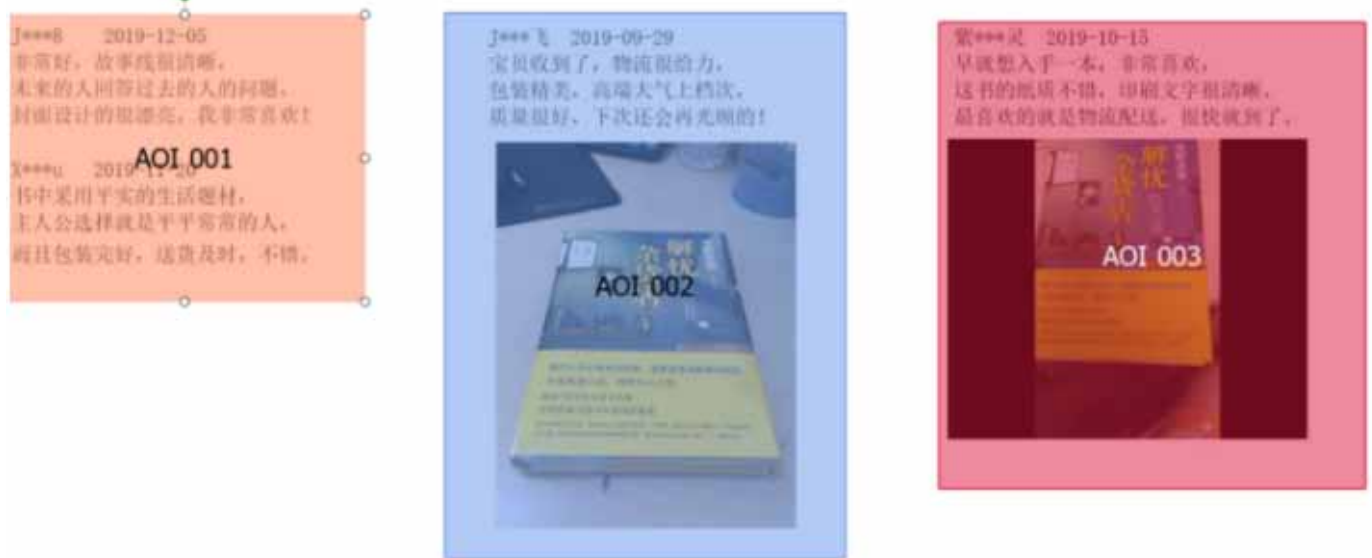

under image-based reviews, there was no significant difference between sensory and nonsensory goods $\left(\mathrm{M}_{\text {sensory }}=209.48\right.$ versus $\left.\mathrm{M}_{\text {nonsensory }}=227.07, \mathrm{t}=-0.833, \mathrm{p}=0.410>0.05\right)$. And in the context of the video-based reviews, the results of sensory goods and nonsensory goods showed no significant difference $\left(\mathrm{M}_{\text {sensory }}=267.29\right.$ versus $\left.\mathrm{M}_{\text {nonsensory }}=222.42, \mathrm{t}=1.672, \mathrm{p}=0.112>0.05\right)$. Finally, the study also compared the different degrees of each presentation format on purchase intention when faced different products. Text-based reviews provided greater impact for nonsensory goods than sensory goods (34.91\%). Image-based reviews provided greater impact improvement for nonsensory goods than sensory goods $(8.40 \%)$. Video-based reviews provided greater impact improvement for sensory goods than nonsensory goods (20.17\%). The result suggested that the moderation effect of product type.

Figure 5. Heat map of sensory goods

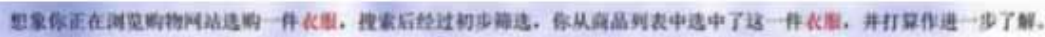

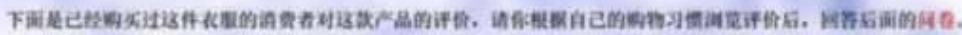

jo6e 2019-12-14

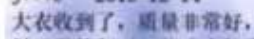

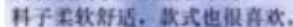

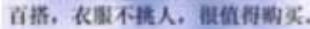

及e*68 2019-11-28

mis m k k

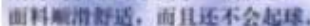

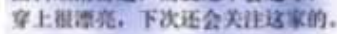
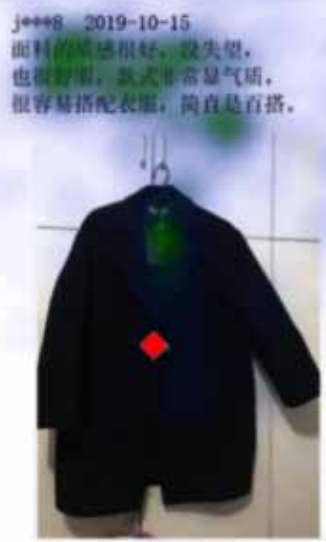

A*เา 2019-10-26

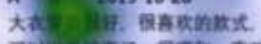

ब.

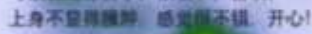

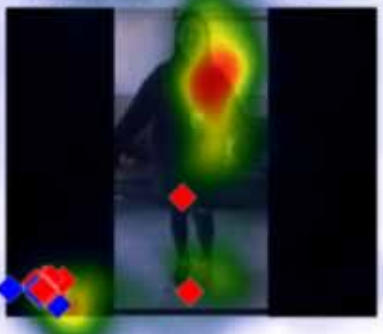




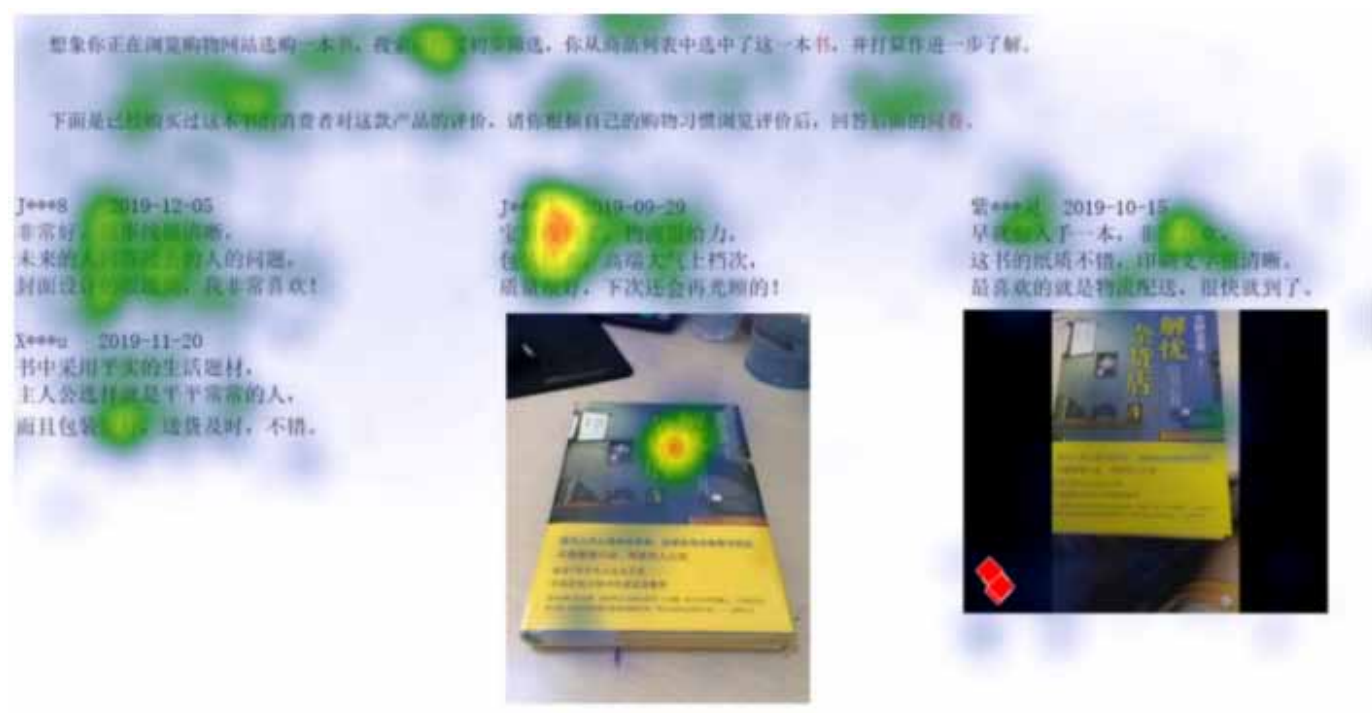

In sum, the results above mentioned supported $\mathrm{H} 4 \mathrm{a}$, but not supported $\mathrm{H} 4 \mathrm{~b}$ and $\mathrm{H} 4 \mathrm{c}$. For H4b, the results were completely contradictory to the hypothesis, which proved the fixation duration on video-based reviews would be longer for nonsensory to sensory goods. The reasons can be explained for two points as followed. First, from the heat map, Figure 5 and Figure 6, the fixation duration on image-based reviews of the book mostly focused on the text, and for image of the book, most of the subjects were concentrated in the name of the book, which they might be curious about the name. Second, for clothing, the consumers paid more attention to beauty and style, which caused someone directly browsing video-based reviews and ignoring image-based reviews. Referring to H4c, although the results were not significant, the fixation duration on video-based reviews of the sensory goods would be longer than the nonsensory goods. From the heat map of Figure 5 and Figure 6 , in the videobased reviews, the more red and yellow presented on video for sensory goods, but more yellow and green showed on text for nonsensory goods. In other words, no significance of the video-based reviews on fixation duration for the subjects were concerned about the different contents, which manifested the video were focused for sensory goods and the text were paid attention for nonsensory goods.

To more objectively prove the explanations mentioned above, the authors redivided the area of interest (AOI), which classified all texts into AOI 001', the only image into AOI 002', and only video into AOI 003'. And then the study reused t-test. The H4a still was supported $\left(M_{\text {sensory }}=151.11\right.$ versus $\left.\mathrm{M}_{\text {nonsensory }}=219.10, \mathrm{t}=-3.022, \mathrm{p}<0.01\right)$. Although $\mathrm{H} 4 \mathrm{~b}$ yet was not supported $\left(\mathrm{M}_{\text {sensory }}^{\text {sensory }}=201.96\right.$ versus $\left.\mathrm{M}_{\text {nonsensory }}^{\text {nonsensory }}=214.14, \mathrm{t}=-0.558, \mathrm{p}=0.580>0.05\right)$, the mean of fixation duration of nonsensory product $\left(M_{\text {nonsensory }}=214.14\right)$ was smaller than the above mentioned $\left(M_{\text {nonsensory }}=227.07\right)$, which partly indicated the reason of no support for $\mathrm{H} 4 \mathrm{~b}$ was that the subjects more focused on the text of the image-based reviews of the book. And $H 4 c$ was supported $\left(M_{\text {sensory }}=278.31\right.$ versus $M_{\text {nonsensory }}=224.32, t=2.693$, $\mathrm{p}<0.05$ ), which tested the reason of no support for $\mathrm{H} 4 \mathrm{c}$ above that the video were focused for sensory goods and the text were paid attention for nonsensory goods.

Moreover, the authors analysed the data from different levels to prove the moderation effect of product type. For sensory goods, video-based reviews had higher positive influence than image-based reviews on consumers' fixation duration $\left(\mathrm{M}_{\text {video }}=278.31\right.$ versus $\left.\mathrm{M}_{\text {image }}=201.96, \mathrm{t}=-3.165, \mathrm{p}<0.01\right)$, and image-based reviews provided greater positive impact than text-based reviews on consumers' fixation duration $\left(\mathrm{M}_{\text {text }}=151.11\right.$ versus $\left.\mathrm{M}_{\text {image }}=201.96, \mathrm{t}=-2.212, \mathrm{p}<0.05\right)$. But for nonsensory goods, the effect 
Table 5. The descriptive statistics of average fixation duration

\begin{tabular}{||l|l|l|c|}
\hline \multirow{4}{*}{ Product type } & Presentation formats & $\mathrm{M}$ & $\mathrm{SD}$ \\
\hline \multirow{3}{*}{ Sensory goods } & Text-based reviews & 161.91 & 78.79 \\
\cline { 2 - 4 } & Image-based reviews & 209.48 & 74.45 \\
\cline { 2 - 4 } & Video-based reviews & 267.29 & 107.88 \\
\hline \multirow{3}{*}{ Nonsensory goods } & Text-based reviews & 218.44 & 74.35 \\
\cline { 2 - 4 } & Image-based reviews & 227.07 & 56.64 \\
\cline { 2 - 4 } & Video-based reviews & 222.42 & 51.45 \\
\hline
\end{tabular}

of different reviews presentation formats almost no difference on fixation duration $\left(\mathrm{M}_{\text {video }}=224.32\right.$ versus $\mathrm{M}_{\text {image }}=214.14$ versus $\mathrm{M}_{\text {text }}=151.11$ ).

\section{CONCLUSION AND DISCUSSION}

The development of review presentation formats from text-based reviews to image-based reviews even video-based reviews, which not only reflected the vendors attached great importance to the formats, but the increasing demand of consumers for information. Obviously, with the diversification of product types, in order to enable consumers more convenient to find the useful information of corresponding product type, online reviews undoubtedly have been a very important part. Therefore,

Figure 7. Interaction effect between presentation format and product type

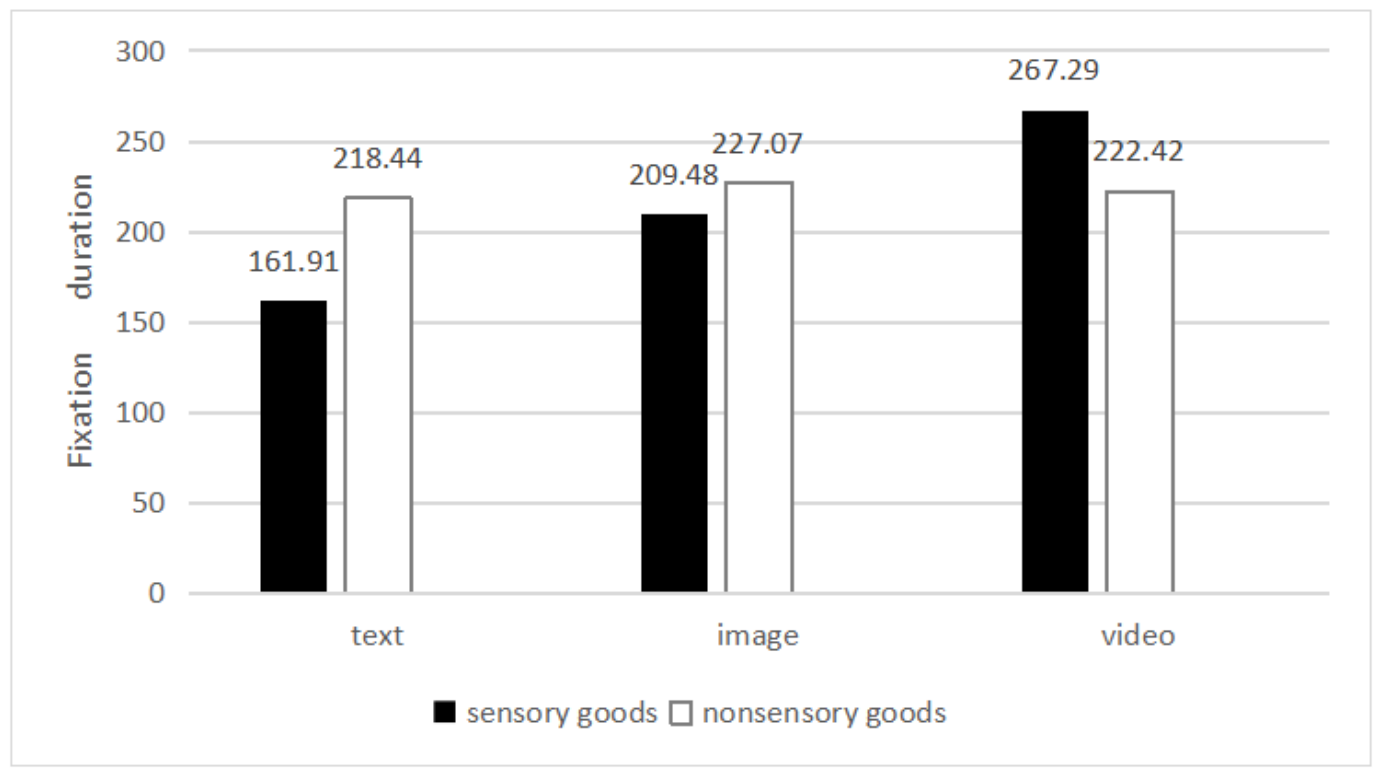


in this study, the authors mainly through two experiments and four hypotheses proposed whether the different review presentation formats have different effects on purchase intention, and also put forward the moderation effect of product type.

The results of $\mathrm{H} 1$ and $\mathrm{H} 2$ suggested different presentation formats exactly had different effects on purchase intention, which proved the question was worth studying. Specifically, video-based reviews have the greatest impact on purchase intention, which is conforming to the actual situation. The annual report of JD reminded video-based reviews have improved the conversion rate of additional purchase, which is in line with the demand of consumers for more product information. Image-based reviews followed, which manifested consumers were more vulnerable to the influence of dynamic and multisensory information.

The results of $\mathrm{H} 3$ showed the moderation effect of product type, which also confirmed consumers had more demand for sensory goods, which is identical with the product attributes and the subjective feelings. The results of $\mathrm{H} 4$, using eye tracking experiment from different aspects, demonstrated different review presentation formats were suitable for different product type. The text-based reviews provided more information of coreness and de-backgroundization, which more matched nonsensory goods. The image-based and video-based reviews could offer intuitive and multisensory information, which were appropriate for sensory goods.

\section{THEORETICAL AND MANAGEMENT CONTRIBUTIONS}

The study focused on the influence of review presentation formats on purchase intention, and explored the moderation effect of product type. This study extended perspective of the impact of online reviews on consumers' purchase decisions. In the past, most of the researchers only focused on the impact of text-based reviews or image-based reviews. With the popularity of smart devices such as mobile phones, uploading images and videos became more and more simple. Consumers' awareness of sharing was becoming stronger, and there were more and more reviews in the formats of images and videos. The study focused on the impact of text reviews, image reviews and video reviews on consumers' purchase intention, which was closer to the reality. In addition, the study broke through the traditional classification method of product types in online reviews, and no longer used experience and search products. The classification of sensory and nonsensory products was closer appropriate to the characteristics of different presentation formats.

The findings of the research had some management contributions. Platforms or vendors aroused consumers to post more images and videos, since image-based and video-based reviews generated more positive effects on purchase intention. For example, online vendors could adopt differentiated incentives to encourage customers who have purchased the products to actively upload reviews with images and videos, and give more rewards to consumers who uploaded videos. The results had also shown that for different product type, presentation formats generated different influence on purchase intention, and obtained the optimal combination of products and online reviews. Therefore, platforms or vendors do not need to continuously and blindly encourage consumers to show images or videos, and should be treated differently according to the product types. For sensory goods, they should attach importance to the sensory information, so encourage consumers to upload image-based or video-based reviews. For nonsensory goods, consumers demanded more objective information, and stimulated consumers to supply text-based reviews.

In a word, platforms or vendors could utilize review presentation formats to enhance the conversion rate of additional purchase. Through reasonable planning and improvement mechanism of online reviews, on the one hand can better eliminate the information asymmetry, on the other let consumers participate in the process of improving mechanism of online reviews, which is helpful to improve the credibility and persuasiveness of information. 


\section{LIMIITATIONS ANG DIRECTIONS FOR FURTHER RESEARCH}

The study also has some limitations. In the research, the presentation formats merely considered the positive reviews for each experimental context. However, in practice, it is almost impossible to be only positive reviews in the review system, negative reviews would usually be existing. Maybe the effects of negative reviews would be more significant than positive reviews. Therefore, further study can take the negative reviews into account to extend this research.

Second, product the authors selected acquired from the trading platform, but with the development of e-commerce platform, social platforms had also appeared, such as little red book in China. Maybe the type of platform had an impact on consumers' perception. In addition, all of the participants were undergraduate students in the experiment. If further research chooses other consumers of different vocations or ages, the conclusion would be better.

Finally, there were barely few subjects in eye-tracking experiment as restricted by vision and other conditions. Although the basic requirements of number had been met, further researches should expand sample size to make the conclusion more stable. In eye-tracking experiment, the arrangement of stimulus materials was in the form of left, middle and right, which not considered the impact of position, so further study could take the position into account.

\section{ACKNOWLEDGMENT}

This research is supported by the National Natural Science Foundation of China through grant 71771184. It is also supported by Humanities and Social Science Talent Plan in Shaanxi through grant ER42015060002. Yuming Liu is the corresponding author of this paper. 


\section{REFERENCES}

Ahmad, S. N., \& Laroche, M. (2016). Analyzing electronic word of mouth: A social commerce construct. International Journal of Information Management, 37(3), 202-213. doi:.2016.08.00410.1016/ j.ijinfomgt

Awad, N. F., \& Ragowsky, A. (2008). Establishing trust in electronic commerce through online word of mouth: An examination across genders. Journal of Management Information Systems, 24(4), 101-121. doi:10.2753/ MIS0742-1222240404

Baal, S. V., \& Dach, C. (2005). Free riding and customer retention across retailers' channels. Journal of Interactive Marketing, 19(2), 75-85. doi:10.1002/dir.20036

Bar, M. (2004). Visual objects in context. Nature Reviews. Neuroscience, 5(8), 617-629. doi:10.1038/nrn1476 PMID: 15263892

Botha, E., \& Reyneke, M. (2015). The influence of social presence on online purchase intention: An experiment with different product types. Developments in Marketing Science: Proceedings of the Academy of Marketing Science, 180-183. doi:10.1007/978-3-319-24184-5_49

Buckner, R. L., Kelley, W. M., \& Petersen, S. E. (1999). Frontal cortex contributes to human memory formation. Nature Neuroscience, 2(4), 311-314. doi:10.1038/7221 PMID:10204536

Burke, R. R. (2002). Technology and the customer interface: What consumers want in the physical and virtual store. Journal of the Academy of Marketing Science, 30(4), 411-432. doi:10.1177/009207002236914

Bywaters, M., Andrade, J., \& Turpin, G. (2004). Determinants of the vividness of visual imagery: The effects of delayed recall, stimulus affect and individual differences. Memory (Hove, England), 12(4), 479-488. doi:10.1080/09658210444000160 PMID:15487543

Chae, S. W., \& Lee, K. C. (2013). Exploring the effect of the human brand on consumers' decision quality in online shopping: An eye-tracking approach. Online Information Review, 37(1), 83-100. doi:10.1108/14684521311311649

Childers, T. L., \& Jiang, Y. (2008). Neurobiological perspectives on the nature of visual and verbal processes. Journal of Consumer Psychology, 18(4), 264-269. doi:10.1016/j.jcps.2008.09.010

Chiu, C. M., Wang, E., Fang, Y. H., \& Huang, H. Y. (2013). Understanding customers' repeat purchase intentions in b2c e-commerce: The roles of utilitarian value, hedonic value and perceived risk. Information Systems Journal, 24(1), 85-114. doi:10.1111/j.1365-2575.2012.00407.x

Citrin, A. V., Stem, D. Jr, Spangenberg, E. R., \& Clark, M. J. (2003). Consumer need for tactile input: An internet retailing challenge. Journal of Business Research, 56(11), 915-922. doi:10.1016/S0148-2963(01)00278-8

Coyle, J. R., \& Thorson, E. (2001). The Effects of progressive levels of interactivity and vividness in web marketing sites. Journal of Advertising, 30(3), 65-77. doi:.1067364610.1080/00913367.2001

Cui, G., Lui, H., \& Guo, X. (2012). The effect of online consumer reviews on new product sales. International Journal of Electronic Commerce, 17(1), 39-58. doi:10.2753/JEC1086-4415170102

Dai, B., Forsythe, S., \& Kwon, W. S. (2014). The impact of online shopping experience on risk perceptions and online purchase intentions: the moderating role of product category and gender. Journal of Electronic Commerce Research, 15(1), 13-24. doi:http://hdl.handle.net/10415/1338

Degeratu, A. M., Rangaswamy, A., \& Wu, J. (2000). Consumer choice behavior in online and traditional supermarkets: The effects of brand name, price, and other search attributes. International Journal of Research in Marketing, 17(1), 55-78. doi:10.1016/S0167-8116(00)00005-7

Duan, W., Gu, B., \& Whinston, A. (2008). The dynamics of online word-of-mouth and product sales-An empirical investigation of the movie industry. Journal of Retailing, 84(2), 233-242. doi:10.1016/j.jretai.2008.04.005

Duque, A., \& Vázquez, C. (2015). Double attention bias for positive and negative emotional faces in clinical depression: Evidence from an eye-tracking study. Journal of Behavior Therapy and Experimental Psychiatry, 46, 107-114. doi:10.1016/j.jbtep.2014.09.005 PMID:25305417

Ehmke, C., \& Wilson, S. (2007). Identifying web usability problems from eye-tracking data. British Hci Group Conference on Hci: Hcibut Not As We Know It. DBLP. doi:10.14236/ewic/HCI2007.12 
Elsamari, B., \& Mignon, R. (2016). The influence of social presence on online purchase intention: an experiment with different product types. Development in marketing science: proceedings of the academy of marketing science, 180-183. 10.1007/978-3-319-24184-5_49

Fiore, A. M., Jin, H. J., \& Kim, J. (2005). For fun and profit: Hedonic value from image interactivity and responses toward an online store. Psychology and Marketing, 22(8), 669-694. doi:10.1002/mar.20079

Gefen, D., \& Straub, D. W. (2004). Consumer trust in B2C e-Commerce and the importance of social presence: Experiments in e-Products and e-Services. Omega, 32(6), 407-424. doi:.omega.2004.01.00610.1016/j

Geschwind, N. (1979). Specializations of the human brain. Scientific American, 241(3), 180-199. doi:10.1038/ scientificamerican0979-180 PMID:493918

Glaser, W. R. (1992). Picture naming. Cognition, 42(1-3), 61-105. doi:10.1016/0010-0277(92)90040-O PMID:1582161

Hassanein, K., \& Head, M. (2005). The impact of infusing social presence in the web interface: An investigation across product types. International Journal of Electronic Commerce, 10(2), 31-55. doi:10.2753/JEC10864415100202

Huang, P., Lurie, N. H., \& Mitra, S. (2009). Searching for experience on the web: An empirical examination of consumer behavior for search and experience goods. Journal of Marketing, 73(1), 55-69. doi:10.1509/ jmkg.73.2.55

Hughes, A., Wilkens, T., Wildemuth, B. M., \& Marchionini, G. (2003). Text or pictures? An eyetracking study of how people view digital video surrogates. International Conference on Image and Video Retrieval, 271 - 280. doi:10.1007/3-540-45113-7_27

Jiang, Z., \& Benbasat, I. (2007). The effects of presentation formats and task complexity on online consumers' product understanding. Management Information Systems Quarterly, 31(3), 475-500. doi:10.2307/25148804

Joann, P., \& Childers, T. L. (2003). To have and to hold: The influence of haptic information on product judgements. Journal of Marketing, 67(2), 35-48. doi:10.1509/jmkg.67.2.35.18612

Just, M. A., \& Carpenter, P. A. (1976). Eye fixations and cognitive processes. Cognitive Psychology, 8(4), 441-480. doi:10.1016/0010-0285(76)90015-3

Keng, C. J., Chang, W. H., Chen, C. H., \& Chang, Y. Y. (2016). Mere virtual presence with product experience affects brand attitude and purchase intention. Social Behavior and Personality: An International Journal, 44(3), 431-444.doi:info:doi/10.2224/sbp.2016.44.3.431

Lee, E. J., \& Park, J. (2014). Enhancing virtual presence in e-tail: Dynamics of cue multiplicity. International Journal of Electronic Commerce, 18(4), 117-146. doi:10.2753/JEC1086-4415180405

Lee, E. J., \& Shin, S. Y. (2014). When do consumers buy online product reviews? effects of review quality, product type, and reviewer's photo. Computers in Human Behavior, 31, 356-366. doi: .10.05010.1016/j.chb.2013

Levie, W. H., \& Lentz, R. (1982). Effects of text illustrations: A review of research. Educational Technology Research and Development, 30(4), 195-232. doi:10.1007/BF02765184

Li, H., Daugherty, T., \& Biocca, F. (2003). The role of virtual experience in consumer learning. Journal of Consumer Psychology, 13(4), 395-407. doi:10.1207/S15327663JCP1304_07

Lin, L. Y., \& Chen, Y. F. (2005). The effects of price promotion, perceived value and store image on consumers purchase intention: A case of 3C chain home appliances in Taipei area. Journal of Management Inquiry, 10, 51-85. http://ir.nou.edu.tw/bitstream/987654321/593/1/H1003.pdf

Liu, Y., \& Du, R. (2019). The effects of image-based online reviews on customers' perception across product type and gender. Journal of Global Information Management, 27(3), 139-158. doi:10.4018/JGIM.2019070108

Lu, B., Fan, W., \& Zhou, M. (2016). Social presence, trust, and social commerce purchase intention: An empirical research. Computers in Human Behavior, 56, 225-237. doi:10.1016/j.chb.2015.11.057 
Luan, J., Yao, Z., Zhao, F. T., \& Liu, H. (2016). Search product and experience product online reviews: An eye-tracking study on consumers' review search behavior. Computers in Human Behavior, 65, 420-430. doi:10.1016/j.chb.2016.08.037

Mollen, A., \& Wilson, H. (2010). Engagement, telepresence and interactivity in online consumer experience: Reconciling scholastic and managerial perspectives. Journal of Business Research, 63(9), 919-925. doi:10.1016/j. jbusres.2009.05.014

Mudambi, S. M., \& Schuff, D. (2010). What makes a helpful online review? A study of customer reviews on amazon.com. Management Information Systems Quarterly, 34(1), 185-200. doi:10.2307/20721420

Nah, F. H., Eschenbrenner, , \& DeWester, . (2011). Enhancing brand equity through flow and. Management Information Systems Quarterly, 35(3), 731-747. doi:10.2307/23042806

Nelson \& Phillip. (1970). Information and consumer behavior. Journal of Political Economy, 81(2),729-754. $10.1086 / 259630$

Nowlis, S. M., Mandel, N., \& McCabe, D. B. (2004). Effect of a delay between choice and consumption on consumption enjoyment. The Journal of Consumer Research, 31(3), 502-510. doi:10.1086/425085

Orús, C., Gurrea, R., \& Flavián, C. (2016). Facilitating imaginations through online product presentation videos: Effects on imagery fluency, product attitude and purchase intention. Electronic Commerce Research, 17(4), 661-700. doi:10.1007/s10660-016-9250-7

Overmars, S., \& Poels, K. (2015). Online product experiences: The effect of simulating stroking gestures on product understanding and the critical role of user control. Computers in Human Behavior, 51, 272-284. doi:10.1016/j.chb.2015.04.033

Paivio, A., \& Ernest, C. H. (1971). Imagery ability and visual perception of verbal and nonverbal stimuli. Perception \& Psychophysics, 10(6), 429-432. doi:10.3758/BF03210327

Paivio, C. A. (1991). Dual coding theory and education. Educational Psychology Review, 3(3), 149-210. doi:10.1007/BF01320076

Park, D., Lee, J., \& Han, I. (2007). The effect of on-Line consumer reviews on consumer purchasing intention: The moderating role of involvement. International Journal of Electronic Commerce, 11(4), 125-148. doi:10.2753/ JEC1086-4415110405

Park, O. C., \& Hopkins, R. (1992). Instructional conditions for using dynamic visual displays: A review. Instructional Science, 21(6), 427-449. doi:10.1007/BF00118557

Pauwels, K., Leeflang, P. S. H., Teerling, M. L., \& Huizingh, K. R. E. (2011). Does online information drive offline revenues? Only for specific products and consumer segments! Journal of Retailing, 87(1), 1-17. doi:10.1016/j.jretai.2010.10.001

Pieters, W. R. (2000). Eye fixations on advertisements and memory for brands: A model and findings. Marketing Science, 19(4), 297-312. doi:10.1287/mksc.19.4.297.11794

Russo, J. E. (1978). Eye fixations can save the world: A critical evaluation and a comparison between eye fixations and other information processing methodologies. Advances in Consumer Research. Association for Consumer Research (U.S.), 5(1), 561-570. https://web.a.ebscohost.com/ehost/pdfviewer/pdfviewer?vid=1\&sid=73281388$7 \mathrm{~d} 5 \mathrm{a}-4 \mathrm{~d} 8 \mathrm{e}-9 \mathrm{c} 0 \mathrm{e}$

Shin, D. H., \& Shin, Y. J. (2011). Consumers' trust in virtual mall shopping: The role of social presence and perceived security. International Journal of Human-Computer Interaction, 27(5), 450-475. doi:10.1080/1044 7318.2011.552060

Song, K., Fiore, A. M., \& Park, J. (2007). Telepresence and fantasy in online apparel shopping experience. Journal of Fashion Marketing and Management, 11(4), 553-570.doi:info:doi/10.1108/13612020710824607

Stenberg., \& Georg. (2006). Conceptual and perceptual factors in the picture superiority effect. European Journal of Cognitive Psychology, 18(6), 813-847. 10.1080/09541440500412361

Steuer, J. (1992). Defining virtual reality: Dimensions determining telepresence. Journal of Communication, 42(4), 73-93. doi:10.1111/j.1460-2466.1992.tb00812.x 
Stigler, G. J. (1961). The Economics of Information. Journal of Political Economy, 69(3), 213-225. doi:10.1086/258464

Wang, Y. J., \& Minor, M. S. (2008). Validity, reliability, and applicability of psychophysiological techniques in marketing research. Psychology and Marketing, 25(2), 197-232. doi:10.1002/mar.20206

Wang, Y. S., Yeh, C. H., Wang, Y. M., Tseng, T. H., Lin, H. H., Lin, S. H., \& Xie, M. Q. (2019). Investigating online consumers' responses to product presentation modes: Does product type really matter? Internet Research, 29(6), 1233-1255. Advance online publication. doi:10.1108/INTR-07-2017-0258

Xu, P., Chen, L., \& Santhanam, R. (2015). Will video be the next generation of e-commerce product reviews? Presentation format and the role of product type. Decision Support Systems, 73, 85-96. doi:10.1016/j. dss.2015.03.001

Yin, H., Zheng, S., Yeoh, W., \& Ren, J. (2021). How online review richness impacts sales: An attribute substitution perspective. Journal of the Association for Information Science and Technology, asi.24457. Advance online publication. doi:10.1002/asi.24457

Yoo, J., \& Kim, M. (2014). The effects of online product presentation on consumer responses: A mental imagery perspective. Journal of Business Research, 67(11), 2464-2472. doi: .2014.03.00610.1016/j.jbusres

Zhu, F., \& Zhang, X. (2010). Impact of online consumer reviews on sales: The moderating role of product and consumer characteristics. Journal of Marketing, 74(2), 133-148. doi:10.1509/jm.74.2.133

Cong Li is a master student of School of Economics and Management, Xidian University. Her research focuses on consumer online behavior and online review.

Yuming Liu is a lecturer in Xidian University. Her research focuses on customer online behavior and online reviews. $\mathrm{He}$ is the corresponding author of this paper.

Rong Du is a Chair Professor in Xidian University. She was a visiting professor in Georgia State University. Her research has been published in journals such as Journal of Global Information Management, Journal of Strategic Information Systems, European Journal of Operational Research, Chinese Management Studies, etc. 